\title{
CLOUD COMPUTING ASPECTS ON KNOWLEDGE MANAGEMENT AND SUPPLY CHAIN
}

\author{
Ovidiu Alin DOBRICAN \\ West University of Timisoara, Romania \\ ovidiu.dobrican@e-uvt.ro
}

\begin{abstract}
Following the trend of globalization, the way in which business is conducted changes, thus increasing the need to implement new ways of managing knowledge, this being facilitated by the development of new information and interconnection technologies. In this regard, we will try to highlight some aspects related to the impact of Cloud computing $(C C)$ on Knowledge Management (KM) and Supply chain (SC). Cloud computer-based platforms help participants in better knowledge management in all SC components, from manufacturers, suppliers, distributors, traders to the final consumer. A new challenge is the implementation of artificial intelligence (AI) in SC management.
\end{abstract}

Keywords: Cloud Computing, Supply Chain, Knowledge management

JEL classification: M11

DOI: $10.24818 / \mathrm{ie} 2020.02 .04$

\section{Introduction}

The organizations that want to deal with requirements and challenges of the market, need to manage knowledge, whereas the management should be tailored to individual needs and capabilities, as well as strategic objectives of the company. Knowledge management strategy should be based on three elements: people, technology and processes. Its implementation requires the integration of knowledge management processes with the strategic objectives of the organization and business processes, operations in the social dimension - concerning the values and good practices cultivated in this area, and the provision of tools (modern technologies) necessary for the effective management of resources and knowledge processes.

Extended supply chains require more coordination through measures such as management of relationships with suppliers, management of internal processes, and management of customer relationships. Effective management of these elements requires significant changes in business strategies and encourages the use of new technologies [1]. Any organization seeks to be reliable, efficient, responsive, sustainable, etc. These goals cannot be achieved without a good $\mathrm{KM}$. This level of management allows him to excel on all levels because the one who manages well his knowledge, both explicit only implicit, can also wonderfully manage its resources without any problems or obstacles. It is also a critical factor in supply chain management, as it plays an important part in the orchestration of various supply chain activities such as joint business plans and demand forecasts [2].

Globalization is forcing organizations to adopt new styles of conducting business. The constant development of technology, in turn, causes the processes in enterprises to become more complicated, due to which the company is not always able to satisfy the requirements associated with owning, acquiring and developing the appropriate resources, including skills, knowledge and qualifications.

A supply chain includes three functions: the supply of materials to a manufacturer, the manufacturing process and the distribution of finished goods through a network of distributors 
and retailers to a final customer. At the operational level, a supply chain supports three types of flows: financial flows, material flows and information flows. These flows require careful planning, collaboration and close coordination between the partners as well as the efficient use of IT by the members of the network to support those fluxes.

In this context, analysis, evaluation, and interpretation of digital data are ways to create knowledge. Any communication, interaction, and transaction produces new data, so, volumes of information grow rapidly.

A client on the Internet can speak with numerous servers in the meantime and these servers' trade data among themselves [3]. This naturally decreases the cost of organizational expenses and offers more capable practical abilities. The gradually removal of software license costs, hardware costs and support costs individually gives extraordinary adaptability to the corporate administration.

Cloud computing in SCM enables organizations to acquire SCM functionalities at lower upfront cost, supports highly distributed operational processes at low cost if the SaaS provider has already built the integrations with supply chain partners, makes possible a faster time to deployment, increases the business value by enabling the companies to innovate at a lower cost, and increases agility to respond to business requirements. [4]

With CC, companies only pay for the amount of server resources used. In addition, new servers can be added on-demand with or without additional charges. This is useful in cases with large fluctuations in demand. With each additional order comes the need for extra bandwidth and processing capability. Within minutes a supply chain management provider can extend services with a cloud host in order to grow in capability. [5]

In the literature, there are several studies that have been developed to identify, for example, the impact of the knowledge management on the performance of the organization or to show the effect of the sharing of knowledge and information on the performance of the SC [6], [7].

Considering, on the one hand, that Artificial Intelligence (AI) refers to systems that mimic the forms of human knowledge related to learning, reasoning and self-rectification and on the other hand, having a large volume of data available in the cloud, AI can be used in pattern identification, in obtaining and managing new knowledge, in decision making, by all actors in a distribution chain.

\section{2. $\mathrm{KM}$ in the $\mathrm{CC}$}

$\mathrm{CC}$ can provide $\mathrm{KM}$ services in the various aspects: a better DM process, increasing profitability, reducing the obtaining of a good decision for the growth of productivity, gaining a competitive advantage. [1]

Three basic models of cloud computing: IaaS - Infrastructure as a Service, PaaS - Platform as a Service and SaaS - Software as a Service can help organizations develop new models of knowledge management, collaborate with other organizations and facilitate the exchange of knowledge, as we can see in Figure 1. Cloud computing, according to [1], not only provides an excellent location to manage data, information and knowledge, but also provides a platform that can be used to make them available on demand, as well as other resources (networks, servers, storage, applications and services). 


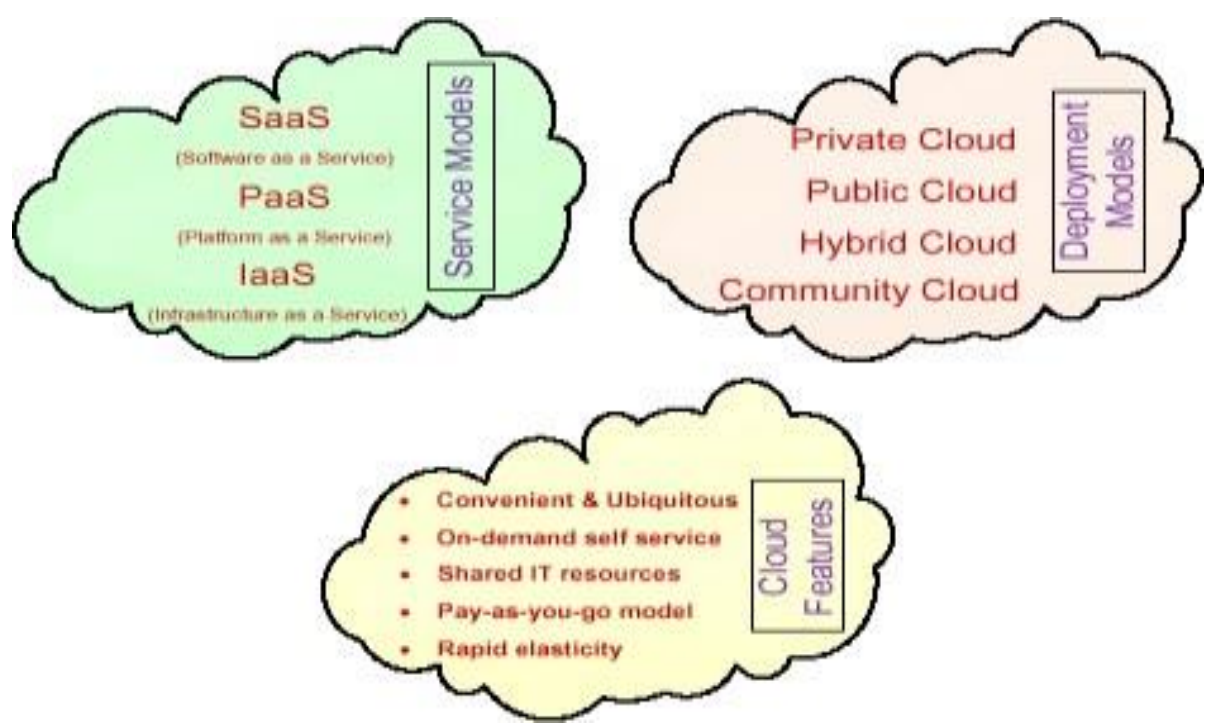

Figure 1. Cloud Service Models, Deployment Models and Cloud Features (Source: [1])

Among the benefits of the integration of cloud computing with the system for knowledge management, there are: cost reduction, adaptation of new practices, discovery of new business models, and providing knowledge as a service, KaaS as a subtype SaaS [1].

In [8] the authors propose the use of cloud technology to provide KM, which can be widely used within the framework of business intelligence and competitive intelligence. The authors illustrate the architecture of KMaaS (Knowledge Management as a Service) along with detailed services and associations and the relations between them. In this way, KMaaS include KaaS.

According to [8], knowledge can be categorized into:

- tacit knowledge: mental models, experiences of individuals, know-how, perceptions

- explicit knowledge: formal models, rules, procedures, more precise and formal

Tacit knowledge can be categorized into:

- know-how, consisting the practical capability to execute specific activities

- know-who, which involves information about who knows what.

Similarly, explicit knowledge also has been divided into:

- know-what, which is the knowledge about facts close to what is defined information, and easy to transfer

- know-why, which refers to scientific knowledge of rules. [8]

They also analyze how different cloud models can be used for KM in the cloud environment and predict their application scenarios and examine the relationship between the use of these models and the access to knowledge, as we can see in Table 1.

Table 1. Access to knowledge in cloud models (Source: [8])

Type of cloud

Private

Public

Community

Hybrid

\section{Explicit knowledge}

Local/limited

Very large

Shared/limited

Depends on the cloud types included
Tacit knowledge

Local/ very limited

Extremely large

Shared/unlimited

Depends on the cloud

types included

In private clouds access to explicit knowledge is local and limited to the organization that owns the cloud. In fact, it seems to have little effect on the access to explicit knowledge, since there is little difference between a private cloud and a local knowledge management system since a KMaaS deployed on a private cloud seems to have little effect on accessing tacit knowledge, 
as well, since it is private. On the contrary, in a publicly-deployed cloud that implements a $\mathrm{KMaaS}$, great levels of access to tacit and explicit knowledge is provided, this is more outstanding for tacit knowledge which is inherently resident in more resources over the cloud users (humans' minds). Community clouds stand in a position in between the two above, since it is neither fully private nor fully public, but shared among definite organizations. Therefore, access to tacit and explicit knowledge is neither as limited as in private clouds, nor is it as open as in public clouds, however, tacit knowledge is more accessible, because of the mentioned reason stated for public clouds. The access level to knowledge in hybrid clouds depend on the combination of clouds that comprise a hybrid cloud, and thus it is complex to analyse. [8]

\section{CC use in the SC}

$\mathrm{CC}$ can be utilized in a wide range of designs and structures by different individuals from different associations, which can make the innovation even more useful in a collaborative supply chain context. The idea of cloud-based technologies makes them scalable, rapidly deployable, and reconfigurable to meet varying authoritative needs and requests [9]. This virtual platform can reduce the paper work, order time, lead time and other activities in the whole process of the supply chain. The players can evaluate the demand which exists in the market and manufacture or order the products which will reduce the inventory costs.

The use of CC in SCM has both advantages and disadvantages.

Advantages:

- $\mathrm{CC}$ has provided on-demand access to information vital for procurement practices, store shelf optimization, sales and operations planning [10];

- inventory information is updated instantly without users having to wait for central servers to populate information across a SC [11].

- companies can use CC to share real-time sales information resulting in closer integration between channels and more efficient supply chain and customer analytics

- with CC, companies only pay for the amount of server resources used. This is useful in cases with large fluctuations in demand. A SC management provider can extend services with a cloud host in order to allow for the growth in capability [5];

- CC provides more secure data backup and recovery capabilities. This is vital to SC management performance as data loss was recently named one of the most significant risks associated with SC relationships [12];

Disadvantages:

- the loss of physical control over data stored in the cloud is a major concern for various companies. To partially mitigate these security concerns, $\mathrm{CC}$ allows companies the choice of public or private clouds [12]. This allows SC partners to balance ease of access to information, as is the case with a public cloud, with reduction of security concerns with use of a private cloud [13];

- other concerns include lack of job security of current in-house IT staff and the sharing of information particularly in a global SC network regarding laws that obliging SaaS providers to keep data in internal borders [11].

Due to the improvement in the latest technology like development of AI it is easier to take any decision for improvement. In the virtual platform the data are stored and AI can be used for taking decision based on the data available in the platform. As a result, intelligence system takes decision and states the necessary solution for the problem. For example, if a product is needed to be send to the customer this system will decide from which particular warehouse this product is needed to be supplied in order to optimize the cost, time and also earn profit at the 
same time for the organization. This intelligent system can be very helpful for the improving the efficiency of the whole process in the supply chain. [14]

\section{Conclusions}

The $\mathrm{KM}$ is a process that helps to achieve the objectives and to improve organizational performance through the creation, accumulation, organization and use of knowledge. Although the sharing of knowledge is important, its effect on the performance of the supply chain depends on how, with whom and when it is shared. However, sharing knowledge within the groups of actors in the supply chain could speed up the workflow, increase the efficiency and productivity of the supply chain, as well as, provide quick access to the knowledge. This is a sensible approach to the needs of customers and a quick response to the needs of the clients changed, so the share of knowledge would gain an advantage to long-term rivalry for the organization [15], [16].

We can conclude the efficient management of knowledge is recommended for an efficient management of the SC. Moreover, once the knowledge is correctly capitalized (categorized, stored), continuously enriched (acquisition and creation) and valued (applied/used, shared, and transferred), their impact is reflected by a considerable minimization of errors and disruptions throughout the SC. Properly managing information, material and financial flows between chain members is of critical importance, as these fluxes can become knowledge that can be used to optimize supply chain relationships. [17] In order to do so, firms must extend their intraenterprise processes to their supply chain partners in order to form inter-enterprise processes.

Knowledge sharing allows partners to orchestrate the operation of supply chain and capture positions of advantage. A very good instrument to do so is exactly CC. Cloud computing's real-time data sharing, lack of requirements in terms of platforms, the ability to increase or decrease server capabilities on-demand as well as scalable service and payment arrangements help to sharing information and increasing supply chain performance.

Cloud based intelligent system and AI technology can be useful for improving the supply chain. With the help of this technology we can bring access the data in the common platform and then analyse and take decisions with AI technology. This common platform will link all the stakeholders in the supply chain process and bring a better process in improving the service efficiency and optimize the cost. In spite of the fact that the AI advancements are drawing in significant considerations in numerous segments, the genuine usage is as yet confronting deterrents. However, once an AI system gets deployed after initial training with historical data, continuation of the information supply turns into an essential issue for advance improvement and development of the system.

\section{References}

[1] M. Rafiq, A. Bashar, A. Shaikh, "Innovative Trends in Knowledge Management: A Cloud Computing Perspective", Proceedings of the First Middle East Conference on Global Business, Economics, Finance and Banking (DUBAI) 2014, [Online] Available http://globalbizresearch.org/Dubai_Conference/pdf/pdf/D459.pdf [Mar. 25, 2020]

[2] G. A. Welker, T. Van der Vaart, D. P. Van Donk, "The influence of business conditions on supply chain information sharing mechanisms: A study among supply chain links of SMEs”, International Journal of Production Economics, vol. 113, no. 2, pp. 706-720

[3] T. Ercan, "Effective use of cloud computing in educational institutions", Procedia- Social and Behavioral Sciences, 2(2), 938-942, 2010

[4] H. Bhoir, R.P. Principal "Cloud Computing for Supply Chain Management", [Online], Available https://www.ijiert.org/admin/papers/1419058459_Volume\%201\%20Issue\% 202.pdf [Mar. 20, 2020]

[5] A. Markim (2015), 8 ways cloud technology is changing the game for supply chain 
management [Online], Available: http://cerasis.com/2015/07/23/cloud-technology-insupply-chain-management/ [Mar 22, 2020]

[6] C.A.A. Rashed, A. Azeem, Z. Halim, "Effect of information and knowledge sharing on SC performance", Journal of Operations and SCM, Vol.3, no 2, pp. 61-77, 2010

[7] J. Rasula, V.B. Vuksic, M.I. Stemberger, "The impact of knowledge management on organisational performance". Economic and Business Review for Central and SouthEastern Europe, vol. 14, no 2, pp. 147, 2012

[8] S. Khoshnevis, F. Rabeifar, "Toward Knowledge Management as a Service in Cloud-Based Environments", International Journal of Mechatronics, Electrical and Computer Technology, Vol. 2(4), Pages 88-110, ISSN: 2305-0543, [Online], Available http://www.aeuso.org/includes/files/articles/Vol2_Iss4_88-110_Toward_Knowledge_ Management_as_a_Se.pdf [Mar 24, 2020]

[9] M. Yazdani, P. Zarate, A. Coulibaly, E.K. Zavadskas, “A group decision making support system in logistics and supply chain management" [Online], Available http://publications.ut-capitole.fr/28501/1/Yazdani_28501.pdf [Mar 23, 2020]

[10] SCMWorld (2013), Supply chain and the future applications [Online], Available: https://www.e2open.com/resources/supply-chain-and-the-future-of-applications [Mar 24, 2020]

[11] J. Gray (2015), Cloud computing and supply chain management. [Online], Available: https://blog.procurify.com/2015/03/05/cloud-computing-and-supply-chain-management/ [Mar 20, 2020]

[12] S. Goode, C. Lin, JC Tsai, JJ Jiang (2015) "Rethinking the role of security in client satisfaction with software-as-a-service (SaaS) providers", Decision Support Systems Vol. 70, pp. 73-85, 2015

[13] E. Yadegaridehkordi, N.A. Iahad, S. Asadi (2015) Cloud computing adoption behaviour: an application of the technology acceptance model, [Online], Available: https://jscdss.utm.my/index.php/files/article/download/30/pdf_35, [Mar 26, 2018]

[14] M. Khalfalla, N. Figay, C.F. Da Silva, P. Ghodous, "A cloud-based platform to ensure interoperability in aerospace industry", Journal of Intelligent Manufacturing, 27(1), 119129,2016

[15] J.H. Cheng, C.H. Yeh and C.W. Tu, "Trust and knowledge sharing in green supply chains". Supply Chain Management: An International Journal, vol. 13, no. 4, pp. 283-295, 2008

[16] B. Sezen, "Relative effects of design, integration and information sharing on supply chain performance”, Supply Chain Management: An International Journal, vol. 13, no 3, pp. 233240, 2008

[17] P. Hadaya, L. Cassivi, "The role of knowledge sharing in a Supply Chain”, In Supply Chain Management and Knowledge Management. Palgrave Macmillan, London, ISBN 978-1-349-36460-2, 2009 